\title{
Etiology of positional plagiocephaly in triplets and treatment using a dynamic orthotic cranioplasty device
}

\section{Report of three cases}

\section{Jeanne K. Pomatto, Timothy R. Littlefield, M.S., Kim Manwaring, M.D., and}

Stephen P. Beals, M.D.

Cranial Technologies, Incorporated, Phoenix, Arizona; Phoenix Children's Hospital, Phoenix, Arizona; and Southwest Craniofacial Center, Phoenix, Arizona

In 1994 a set of triplets presented to the authors for treatment of their positional plagiocephaly with Dynamic Orthotic Cranioplasty (DOC ${ }^{\mathrm{TM}}$ ). The three 8-month-old infants were diagnosed with severe, moderate, and mild plagiocephaly. Only the severe and moderate cases were treated with the DOC band. The mild case was not treated with the DOC band because it was thought that the condition could be addressed through alteration in the child's sleeping position. The child with severe deformation required 8.5 months of treatment with two DOC bands and had significant residual asymmetries at the end of the treatment course. The child with moderate deformity required 2.5 months of treatment with only one DOC band and had excellent correction of the initial asymmetries. The results of their treatment provide a unique forum for discussing the etiology of positional plagiocephaly, as well as those factors that can influence the efficacy of DOC treatment.

\section{Key Words * positional plagiocephaly * dynamic orthotic cranioplasty}

In 1992, the American Academy of Pediatrics[1] published the results of a multi-national investigation that studied the relationship between infant sleeping position and the frequency of sudden infant death syndrome. In this report, the Academy recommended that infants be positioned to sleep either on their backs or sides to reduce the risk of sudden infant death syndrome. Subsequently, the Public Health Service initiated the "Back To Sleep Campaign," which advocated the back or side sleeping of infants.[10]

Following the publication of this report, craniofacial centers around the world began to observe an increase in the number of children presenting with abnormal head shapes.[2,19] Consistent with previous reports, many of these patients were diagnosed as having synostosis of the lambdoid suture and were treated surgically.[11] However, at surgery it was often discovered that the sutures had not prematurely fused, leading many surgeons to question the cause of this deformation. Multiple centers soon concluded that these deformations were positional in nature, developing from the extended time an infant spent supine in a crib, car seat, or infant swing. $[14,16,17]$ This condition was termed positional or deformational plagiocephaly and is often characterized by a parallelogram-shaped head. 
Since 1992, over 750 cases of positional plagiocephaly have been treated with a device known as the Dynamic Orthotic Cranioplasty (DOC ${ }^{\mathrm{TM}}$ ) band. The DOC band is worn around the head and applies mild dynamic pressure to the prominent regions to constrain growth in those areas and encourage growth in the flattened regions (Fig. 1). Initial results of the efficacy of DOC treatment for positional plagiocephaly have been documented by Ripley, et al.[18]

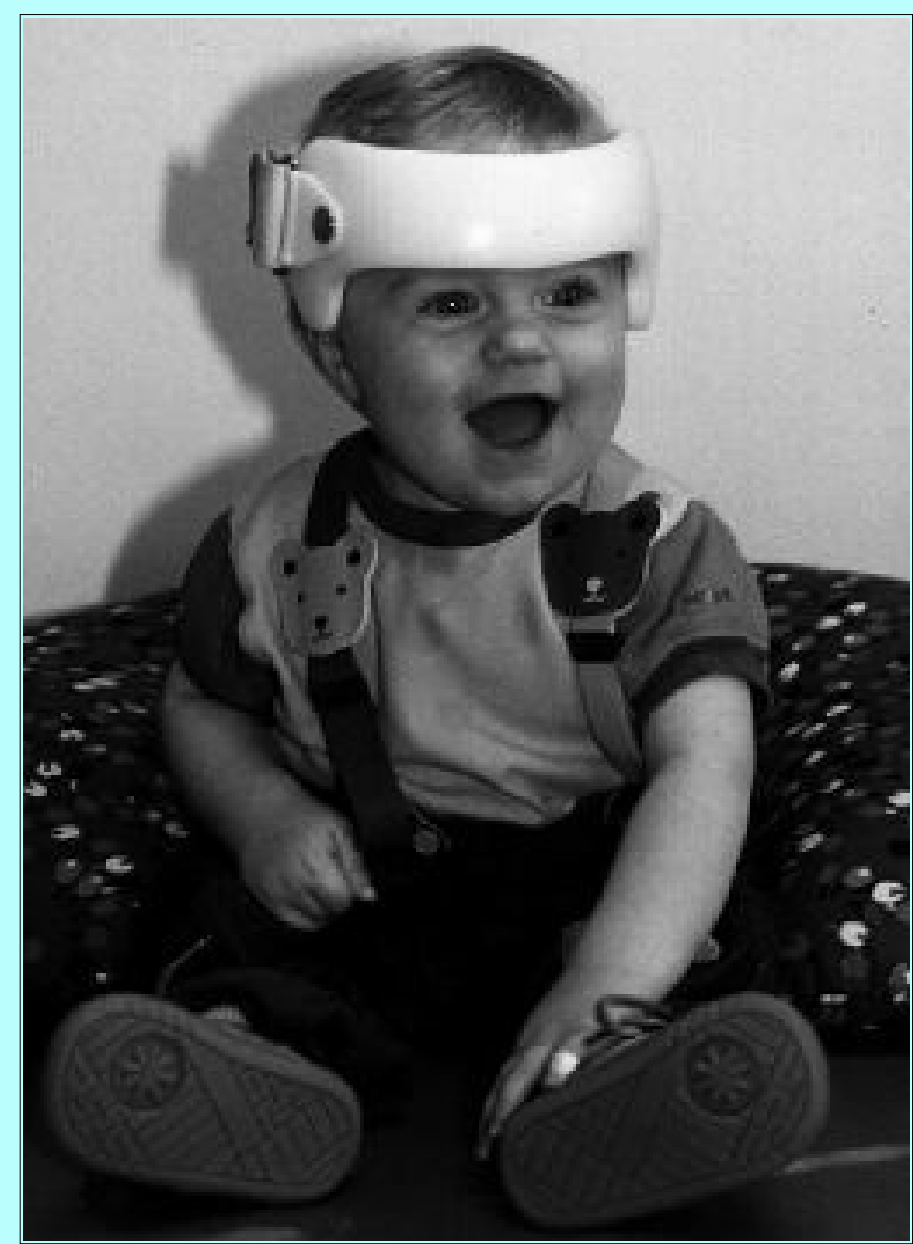

Fig. 1. Photograph showing an infant wearing a DOC band.

In 1994 a set of 8-month-old triplets, each with a different degree of positional plagiocephy, presented for treatment in our office. Two of the three triplets required DOC treatment for their plagiocephaly. The third child was treated by alteration in his sleeping position because his mild condition did not require DOC treatment. Both of the infants treated with the DOC band exhibited a tightness in the left sternocleidomastoid muscle with an associated flattening in the right parietooccipital region and right frontal bossing of the forehead. These infants were followed anthropometrically for 24 months. The results of their treatment provide a unique forum for discussing the etiology of positional plagiocephaly, as well as those factors that can influnece the efficacy of DOC treatment.

\section{CASE REPORTS}

At 8 months of age, the children in Cases 1, 2, and 3 (in order of birth) were referred for Dynamic Orthotic Cranioplasty treatment of their positional plagiocephaly. Entrance into the DOC treatment program had been delayed (optimum entrance age 3-4 months) by the belief that the abnormal shapes would correct on their own if given time. At 8 months it was determined that their asymmetry was progressively getting worse.

These triplets were born prematurely (30 weeks of gestational age) by Cesaerean section that was initiated because of fetal distress in Case 1. All three infants were primarily back sleepers until the time of their entrance into the DOC program. Cases 1 and 2 were diagnosed with positional plagiocephaly severe enough to warrant treatment with a DOC band. The condition of the child in Case 3 was mild and no DOC treatment was prescribed. Cases 1 and 2 were cast and fitted for the DOC band, and anthropometric measurements (as defined by Farkas [8] and Hajnis [9]) in all three infants were made at this time. Figure 2 identifies the key anthropometric landmarks that are used to document the asymmetry of the cranium, face, and skull base. 


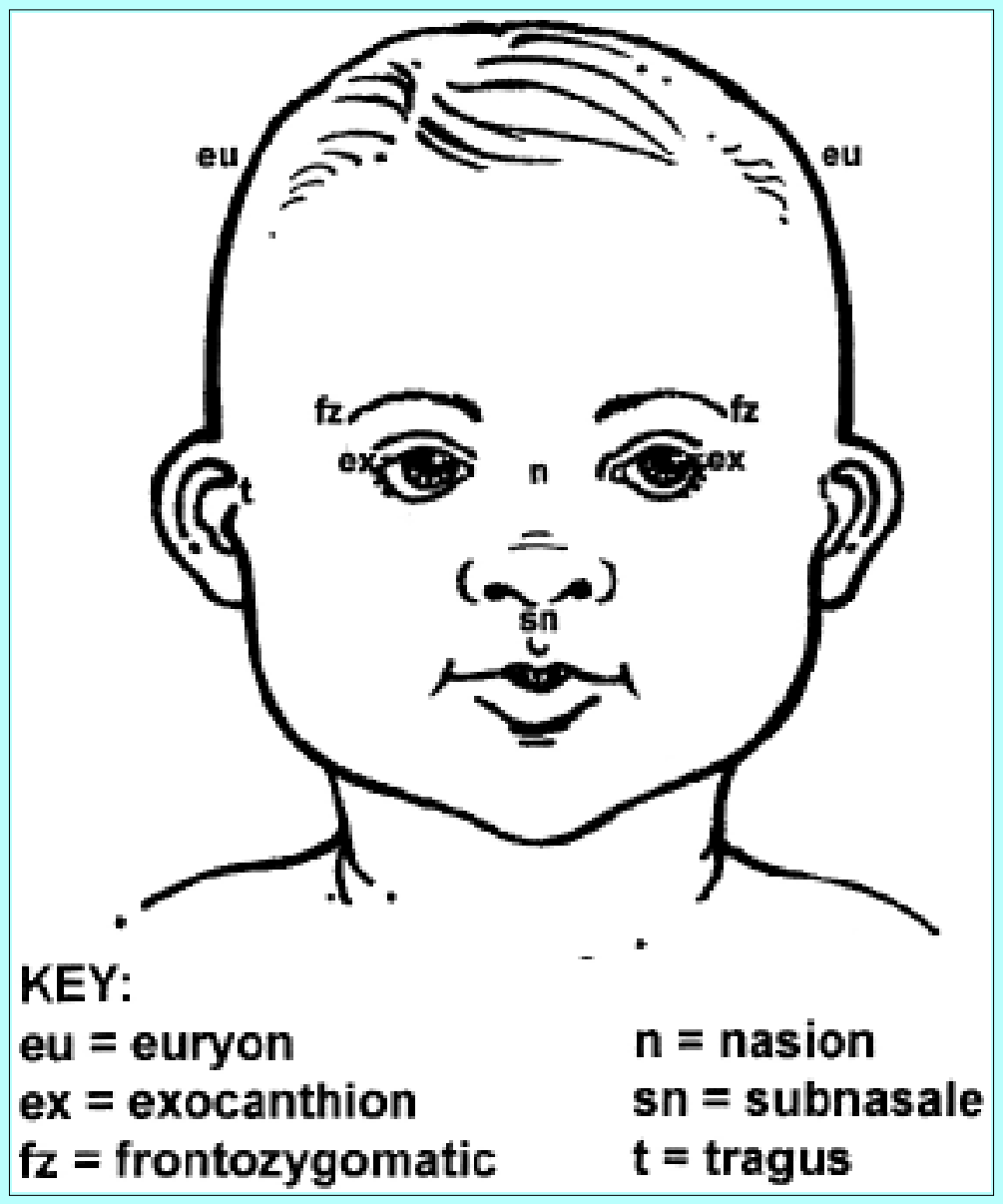

Fig. 2. Schematic drawing illustrating the key anthropometric landmarks used in the evaluation of abnormal head shape. The CVA is calculated from measurements made of the left frontozygomatic (fz) to right euryon (eu) and the right $\mathrm{fz}$ to the left eu. The SBA is calculated from measurements made between the nasion (n) and the right and left tragii ( $t$ ) and subnasale (sn) and the right and left tragii ( $\mathrm{t}$ ). Upper face, or OTDA, is derived from measurements of the right and left exocanthion (ex) to the right and left $t$, respectively.

\section{Case 1}

This 8-month-old boy had been diagnosed with severe positional plagiocephaly, which demonstrated significant flattening of the right parietooccipital region, right frontal bossing of the forehead, and an anteriorly-positioned right ear. He also exhibited a severe tightness of the left sternocleidomastoid muscle. At 8 months of age he was fitted for his first DOC band, and although there was an initial improvement, after 2 months of treatment significant asymmetry of the skull base and cranial vault remained. At 11 months the child was fitted for his second DOC band which he wore until 16.5 months of age. By 15 months of age it was noted that his rate of growth had significantly decreased. Over the course of the treatment, his cranial vault asymmetry (CVA) was corrected from 10 to $4 \mathrm{~mm}$, his skull base asymmetry (SBA) was corrected from 12 to $10 \mathrm{~mm}$, and his orbitotragial depth asymmetry (OTDA) was corrected from 4 to $3 \mathrm{~mm}$. No additional improvement in these asymmetries was noted at his 24 month follow-up evaluation. The parents complied with the recommended neck exercise regimen, which had been prescribed to reduce the tightness in his sternocleidomastoid muscle.

\section{Case 2}

This 8-month-old boy had been diagnosed with moderate positional plagiocephaly and flattening of the 
right occipital region and left forehead. No significant frontal bossing was observed. The child also demonstrated an anterior placement of the right ear with respect to the left and a moderate tightness of the left sternocleidomastoid muscle. This child's moderate plagiocephaly was corrected within 2.5 months of treatment with the DOC band. His SBA was corrected from 6 to $1 \mathrm{~mm}$, and his OTDA was corrected from 1 to $0 \mathrm{~mm}$. No initial asymmetry of the CVA was measured. No further improvement in these asymmetries was noted at his 24 month follow-up evaluation. The parents complied with the neck exercises recommended for this child.

\section{Case 3}

This 8-month-old presented with a mild case of plagiocephaly and flattening in the right occipitoparietal region with no involvement of the forehead. No neck tightness was observed and neither ear was positioned anterior to the other. The parents complied with the directions of the physician to alter the child's sleeping position. This child's initial CVA was $4 \mathrm{~mm}$, and no SBA or OTDA was noted. At the 24-month follow-up evaluation, the CVA had corrected from 4 to $3 \mathrm{~mm}$. The results of these three cases are summarized in Table 1.

\begin{tabular}{|c|c|c|c|}
\hline \multicolumn{4}{|c|}{$\begin{array}{l}\text { TABLE } 1 \\
\text { DIAGNOSIS AND CORRECTION OF FAC HL, SKULL BASE, AND CRANIAL YAULT ASVMMETR ES IN TRIPLETS } \\
\text { WITH DIFFERENT DEGREES OF POSITIONAL PLAGIOCEPHALY }\end{array}$} \\
\hline 'Variatle & Case 1 & Case 2 & Case 3 \\
\hline $\begin{array}{l}\text { diagnosis } \\
\text { treatment time } \\
\text { no. of DOC } \\
\text { bands required }\end{array}$ & $\begin{array}{c}\text { severe plagiocephaly } \\
8.5 \text { mos } \\
2\end{array}$ & $\begin{array}{c}\text { moderate plagiocephal y } \\
2.5 \text { mos } \\
1\end{array}$ & $\begin{array}{c}\text { mild plagioce phaly } \\
\text { no treatment } \\
0\end{array}$ \\
\hline $\begin{array}{l}\text { posterior in wol we- } \\
\text { ment } \\
\text { frontel in wol ie- } \\
\text { ment }\end{array}$ & $\begin{array}{l}\text { se vere rt parieto- } \\
\text { occi pital flattening } \\
\text { It frontal flattening, } \\
\text { rt frontal bossing }\end{array}$ & $\begin{array}{l}\text { moderate it occipital } \\
\text { flattening } \\
\text { It frontal flattening }\end{array}$ & $\begin{array}{l}\text { mild rt parieto- } \\
\text { occipital flattening } \\
\text { none }\end{array}$ \\
\hline neck tightness & $\begin{array}{l}\text { severe It sternodei- } \\
\text { domastoid musde }\end{array}$ & $\begin{array}{l}\text { moderate It sternoclei- } \\
\text { domastoid musde }\end{array}$ & none \\
\hline ear shift & rt anterior $-\mathrm{t}$ & $\mathrm{rt}$ anterior $-\mathrm{t}$ & none \\
\hline CVA correction & $10-4 \mathrm{~mm}$ & $0-0 \mathrm{~mm}$ & $4-3 \mathrm{~mm}$ \\
\hline SBA Correction & $12-10 \mathrm{~mm}$ & $6-1 \mathrm{~mm}$ & $0-0 \mathrm{~mm}$ \\
\hline OTDA Correction & $4-3 \mathrm{~mm}$ & $1-0 \mathrm{~mm}$ & $0-0 \mathrm{~mm}$ \\
\hline $\begin{array}{l}\text { im pro wement in } \\
\text { asymmetry after } \\
\text { treatment }\end{array}$ & none & none & - \\
\hline
\end{tabular}

\section{DISCUSSION}

These unique triplet cases identified the four main factors influencing the development of positional plagiocephaly: 1) intrauterine crowding; 2) premature birth; 3) neck tightness or torticollis; and 4) sleeping position. Additionally, these cases help to identify those factors that affect the efficacy of treatment with the DOC band: 1) initial degree of severity; 2) age of patient at entrance; and 3) lack of self-correction if left untreated. The pre- and posttreatment photographs of the infants in Cases 1 and 2 are shown in Fig. 3 (photographs of the patient in Case 3 were not obtained). 


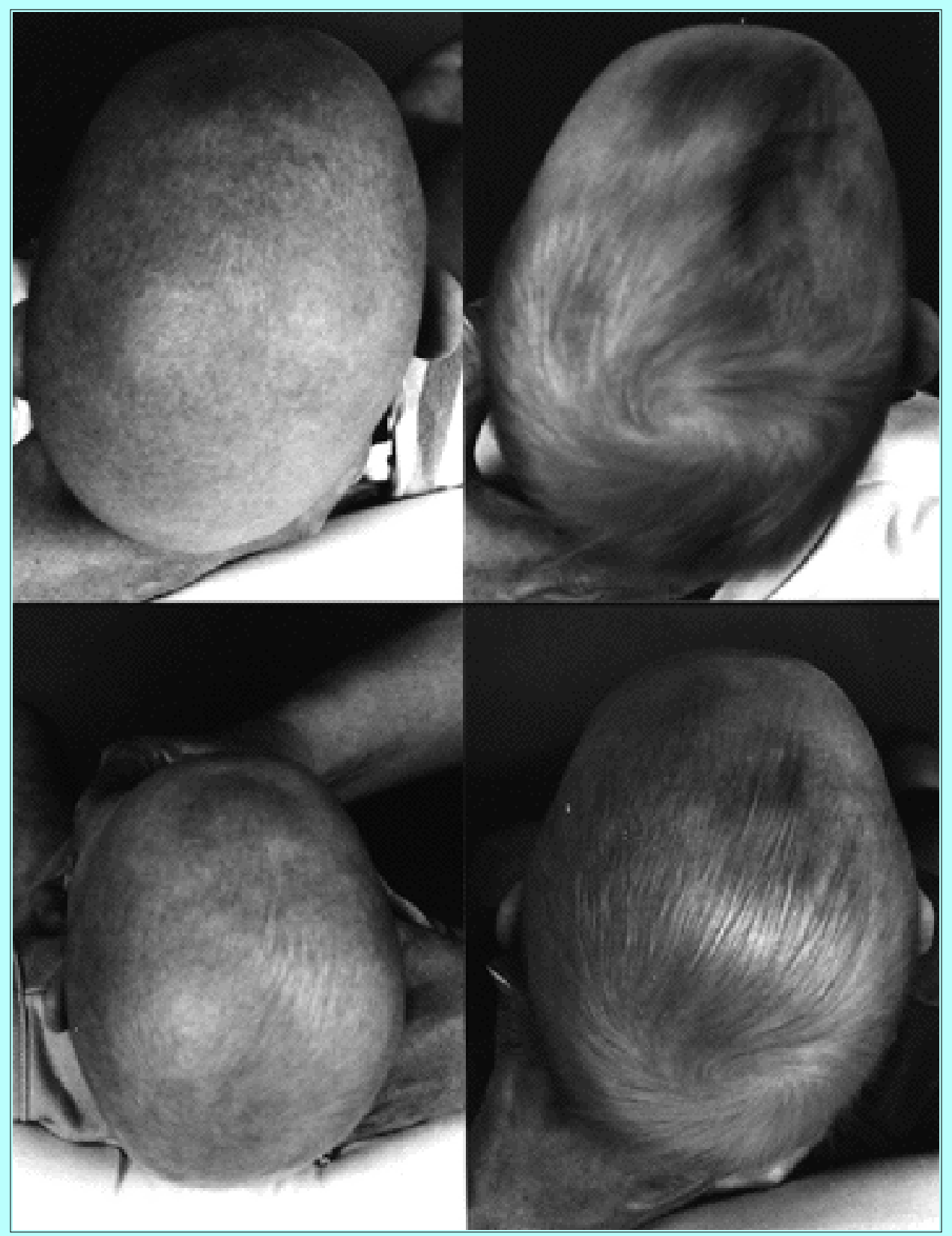

Fig. 3. Upper left: Pretreatment photograph of the infant in Case 1 at 8 months of age. The patient exhibited severe right parietooccipital flattening, left frontal flattening, right frontal bossing, and the right ear anteriorly positioned to the left. Upper right: Posttreatment photograph of the same patient after 8.5 months of treatment with two DOC bands. The residual cranial vault, skull base, and facial asymmetries remain. Lower left: Pretreatment photograph of the infant in Case 2 at 8 months of age. The patient exhibited moderate right occipital flattening, left frontal flattening, and no frontal bossing noted. The right ear was also located anteriorly to the left. Lower right: Posttreatment photograph of the same patient after 2.5 months of treatment with one DOC band.

\section{Etiology of Positional Plagiocephaly}

Molding of the infant head during the birthing process is a common occurrence; the head tends to return to normocephaly within the first 6 weeks of life. However, the development of an abnormal head shape can occur due to many factors, including restrictive intrauterine environment,[3,6] premature birth,[12] torticollis or neck tightness,[7] and sleeping position.[5,14] In Cases 1, 2, and 3 each of these factors may 
have contributed to the development of their plagiocephaly. These triplets experienced a premature delivery, were subject to intrauterine crowding, were all back sleepers, and two of the three had significant neck tightness. To what degree each factor influenced the development of plagiocephaly and why the infant in Case 1 developed a more severe deformity than either of the other two infants is unknown. A strong correlation between neck tightness and positional plagiocephaly is indicated by Case 1 ; this child had the most severe neck tightness and developed the worst plagiocephaly. Also, the flattening of the right parietooccipital region corresponds with the direction the head would turn (to the right) with a tight left sternocleidomastoid muscle. The child in Case 3 who did not have any associated neck tightness developed only a mild case of plagiocephaly. Of the over 750 positional plagiocephaly cases treated since 1992, 33\% had associated neck tightness and $13.5 \%$ were diagnosed with torticollis.

A restrictive intrauterine enviroment also appears to play a significant role in the development of plagiocephaly. Seven and nine-tenths percent of the cases treated with the DOC band since 1992 were multiple births. Compare this with the number of multiple births in the United States, 2.6\% per year,[15] and a strong correlation is suggested.

The relationship between premature birth and plagiocephaly has also been investigated.[3,6,12] The general consensus is that the high incidence of positional plagiocephaly in these infants is not a direct result of their prematurity, but rather it is due to positional molding that occurs in the neonatal intensive care units. The shape of the head that results from this form of molding will not be the typical parallelogram shape; rather, it will be a long, narrow scaphocephalic shape, that develops from the head resting on either parietal side for extended periods of time.

The sleeping position of an infant appears to be the most significant factor influencing the development of plagiocephaly, as documented by the substantial rise in positional plagiocephaly cases reported since the publication of the sudden infant death syndrome report and the "Back to Sleep Campaign." $[2,4,10,11,16,19]$ Of the over 750 cases treated for positional plagiocephaly, 65 to $70 \%$ were children who slept on their backs. The parents of our three patients identified the supine sleeping position as the primary orientation for all of the children.

\section{Efficacy of Treatment With the DOC Band}

The efficacy of treatment with the DOC band depends on many factors, primarily the age at which the patient enters treatment, the initial severity of the associated asymmetries, and the compliance of the parents in following the treatment protocol.

The age an infant enters treatment is important, because the mechanism of correction relies on capturing the rapid growth period of the head to correct the asymmetries. The mild application of pressure in the prominent areas of the skull, restricting growth in those directions, encourages development of the flattened areas. Rapid brain growth routinely occurs between the ages of 3 and 6 months. As this window of rapid growth is passed, the efficacy of treatment with the DOC band will decrease proportionally, and the increasing cranial rigidity will diminish the molding potential.

The initial degree of severity plays a significant role in the effectiveness of treatment. It is often closely tied to the age at which the infant entered treatment, many of the most severe cases being those in which treatment was delayed. Both Cases 1 and 2 entered treatment later than desired, and the period of rapid growth was missed.

As was observed in this set of triplets, the misconception that the abnormal head shape will self-correct if 
left alone often increases the initial severity which must be treated later. Although it is true that the skull molding that occurs during the birthing process does correct to a more normal shape within the first 6 weeks of life, an abnormal head shape should be monitored closely if it has not resolved by 8 to 12 weeks.[13] If the abnormal shape continues to worsen during that period, the child should be refered to a specialist for consultation. The residual asymmetries in these children after treatment with the DOC band did not improve, as measured anthropometrically at 24 and 36 months of age.

\section{Disclosure}

Jeanne K. Pomatto has financial interest in the instrumentation advanced in this article.

\section{References}

1. AAP Task Force on Infant Positioning and SIDS: Positioning and SIDS. Pediatrics 89:1120-1126, 1992

2. Argenta LC, David LR, Wilson JA, et al: An increase in infant cranial deformity with supine sleeping position. J Craniofac Surg 7:5-11, 1996

3. Baum JD, Searls D: Head shape and size of pre-term low-birthweight infants. Dev Med Child Neurol 13:576-581, 1971

4. Bruneteau RJ, Mulliken JB: Frontal plagiocephaly: synostotic, compensational, or deformational. Plast Reconstr Surg 89:21-31, 1992

5. Budreau GK: Postnatal cranial molding and infant attractiveness: implications for nursing. Neonat Network 5:13-19, 1987

6. Clarren SK, Smith DW: Congenital deformities. Pediatr Clin of North Am 24:665-677, 1977

7. Clarren SK, Smith DW, Hanson JW: Helmet treatment for plagiocephaly and congenital muscular torticollis. J Pediatr 94:43-46, 1979

8. Farkas L: Anthropometry of the Head and Face in Medicine. New York: Elsevier, 1981

9. Hajnis K: Kopf-Ohrmuschel-und Handwachstum (Verwendung bei den Operationen der Angeborenen Missbildungen und Unfallsfolgen). Acta Univ Carol [Biol] Praha 24:77, 1974

10. Havens DH; Zink RL: The "Back to Sleep" campaign. J Pediatr Health Care 8:240-242, 1994

11. Huang MHS, Gruss JS, Clarren SK, et al: The different diagnosis of posterior plagiocephaly: true lambdoid synostosis versus positional molding. Plast Reconstr Surg 98:765-774, 1996

12. Largo RH, Duc G: Head growth and changes in head configuration in healthy preterm and term infants during the first six months of life. Helvet Paediatr Acta 32:431-442, 1978

13. Marsh JI, Vannier MW: Cranial deformities, in Marsh JL, Vannier MW (eds): Comprehensive Care for Craniofacial Deformities. St. Louis: CV Mosby, 1985, pp 121-153

14. Moss M: The pathogenisis of artificial cranial deformation. Am J Phys Anthropol 16:269-286, 1958

15. National Center for Health Statistics: Statistics on live births in the United States in 1994. 
16. Ortega B: Some physicians do unnecessary surgery on heads of infants. The Wall Street Journal, Friday, February 23, 1996

17. Persing JA: Occipital deformities. J Craniofac Surg 7:4, 1996 (Editorial)

18. Ripley CE, Pomatto J, Beals SP, et al: Treatment of positional plagiocephaly with dynamic orthotic cranioplasty. J Craniofac Surg 5:150-159, 1994

19. Turk AE, McCarthy JG, Thorne CCHM, et al: The "Back to sleep campaign" and deformational plagiocephaly: is there cause for concern? J Craniofac Surg 7:12-18, 1996

Manuscript received January 9, 1997.

Accepted in final form January 29, 1997.

Address reprint requests to: Jeanne K. Pomatto, Cranial Technologies, Incorporated, 1331 North 7th Street, Suite 170, Phoenix, Arizona, 85006.

$\underline{\text { Click here to view commentary on this article. }}$ 